\title{
Brazilian guidelines for the management of psychomotor agitation. Part 1. Non-pharmacological approach
}

\author{
Leonardo Baldaçara, ${ }^{1,2,3}$ iD Flávia Ismael, ${ }^{1,4,5,6}$ Verônica Leite, ${ }^{1,3,7}$ Lucas A. Pereira, ${ }^{1,8,9,10}$
}

Roberto M. dos Santos, ${ }^{1,11,12}$ Vicente de P. Gomes Júnior, ${ }^{1,13}$ Elie L.B. Calfat, ${ }^{1,14,15}$

Alexandre P. Diaz, ${ }^{16}$ Cintia A.M. Périco, ${ }^{1,5,17}$ Deisy M. Porto, ${ }^{1,18,19}$ Carlos E. Zacharias, ${ }^{1,20,21}$

Quirino Cordeiro, ${ }^{1,14,22}$ Antônio Geraldo da Silva, ${ }^{23,24,25}$ (iD Teng C. Tung ${ }^{1,26}$

${ }^{1}$ Comissão de Emergências Psiquiátricas, Associação Brasileira de Psiquiatria (ABP), Rio de Janeiro, RJ, Brazil. ${ }^{2}$ Universidade Federal do Tocantins (UFT), Palmas, TO, Brazil. ${ }^{3}$ Secretaria de Estado de Saúde do Tocantins, Palmas, TO, Brazil. ${ }^{4}$ Coordenadoria de Saúde Mental, São Caetano do Sul, SP, Brazil. ${ }^{5}$ Faculdade de Medicina do ABC, Santo André, SP, Brazil. ${ }^{6}$ Universidade de São Caetano do Sul, São Caetano do Sul, SP, Brazil. ${ }^{7}$ Secretaria de Saúde do Município de Palmas, Palmas, TO, Brazil. ${ }^{8}$ Faculdade de Tecnologia e Ciências (FTC), Salvador, BA. ${ }^{9}$ Universidade Salvador (UNIFACS), Salvador, BA, Brazil. ${ }^{10}$ Escola Bahiana de Medicina e Saúde Pública (EBMSP), Salvador, BA, Brazil.

${ }^{11}$ Hospital Universitário Lauro Wanderley, Universidade Federal da Paraíba (UFPB), João Pessoa, PB, Brazil. ${ }^{12}$ Pronto Atendimento de Saúde Mental, João Pessoa, PB, Brazil. ${ }^{13}$ Associação Psiquiátrica do Piauí (APPI), Teresina, PI, Brazil. ${ }^{14}$ Faculdade de Medicina da Santa Casa de São Paulo (FCMSCSP), São Paulo, SP, Brazil. ${ }^{15}$ Centro de Atenção Integrada à Saúde Mental, Franco da Rocha, SP, Brazil. ${ }^{16}$ Universidade do Sul de Santa Catarina (UNISUL), Tubarão, SC, Brazil. ${ }^{17}$ Coordenadoria de Saúde Mental, São Bernardo do Campo, SP, Brazil. ${ }^{18}$ Instituto de Psiquiatria de Santa Catarina, São José, SC, Brazil. ${ }^{19}$ Coordenação Estadual de Saúde Mental, Florianópolis, SC, Brazil. ${ }^{20}$ Secretaria de Estado da Saúde de São Paulo, São Paulo, SP, Brazil. ${ }^{21}$ Secretaria de Saúde do Município de Sorocaba, Sorocaba, SP, Brazil. ${ }^{22}$ Coordenação-Geral de Saúde Mental, Álcool e Outras Drogas, Ministério da Saúde, Brazil. ${ }^{23}$ Asociación Psiquiátrica de América Latina (APAL). ${ }^{24}$ ABP, Rio de Janeiro, RJ, Brazil. ${ }^{25}$ Faculdade de Medicina, Universidade do Porto/Conselho Federal de Medicina (CFM), Porto, Portugal. ${ }^{26}$ Instituto de Psiquiatria, Hospital das Clínicas, Faculdade de Medicina, Universidade de São Paulo (USP), São Paulo, SP, Brazil. iD LB https://orcid.org/0000-0002-52018515, iD AGS https://orcid.org/0000-0003-3423-7076

\begin{abstract}
Objective: To present the essential guidelines for non-pharmacological management of patients with psychomotor agitation in Brazil.

Methods: These guidelines were developed based on a systematic review of articles published from 1997 to 2017, retrieved from MEDLINE (PubMed), Cochrane Database of Systematic Review, and SciELO. Other relevant articles identified by searching the reference lists of included studies were also used to develop these guidelines. The search strategy used structured questions formulated using the PICO model, as recommended by the Guidelines Project of the Brazilian Medical Association. Recommendations were summarized according to their level of evidence, which was determined using the Oxford Centre for Evidence-based Medicine system and critical appraisal tools.

Results: We initially selected 1,731 abstracts among 5,362 articles. The final sample included 104 articles that fulfilled all the inclusion criteria. The management of agitated patients should always start with the least coercive approach. The initial non-pharmacological measures include a verbal strategy and referral of the patient to the appropriate setting, preferably a facility designed for the care of psychiatric patients with controlled noise, lighting, and safety aspects. Verbal de-escalation techniques have been shown to decrease agitation and reduce the potential for associated violence in the emergency setting. The possibility of underlying medical etiologies must be considered first and foremost. Particular attention should be paid to the patient's appearance and behavior, physical signs, and mental state. If agitation is severe, rapid tranquilization with medications is recommended. Finally, if verbal measures fail to contain the patient, physical restraint should be performed as the ultimate measure for patient protection, and always be accompanied by rapid tranquilization. Healthcare teams must be thoroughly trained to use these techniques and overcome difficulties if the verbal approach fails. It is important that healthcare professionals be trained in non-pharmacological management of patients with psychomotor agitation as part of the requirements for a degree and graduate degree.

Conclusion: The non-pharmacological management of agitated patients should follow the hierarchy of less invasive to more invasive and coercive measures, starting with referral of the patient to an appropriate environment, management by a trained team, use of verbal techniques, performance of physical and mental assessment, use of medications, and, if unavoidable, use of the mechanical restraint.
\end{abstract}

Systematic review registry number: CRD42017054440.

Keywords: Environmental health; psychomotor agitation; aggression; emergency; mental disorders; patient care team; risk assessment; physical restraint; immobilization

Correspondence: Leonardo Baldaçara, Universidade Federal do Tocantins, Quadra 109 Norte, Avenida NS15, ALCNO-14, Plano Diretor Norte, Campus de Palmas, Bloco BALA I, Medicina, CEP 77001-090, Palmas, TO, Brazil.

E-mail: leonardobaldassara@gmail.com

Submitted May 18 2018, Submitted Aug 03 2018, Epub Dec 062018.
How to cite this article: Baldaçara L, Ismael F, Leite V, Pereira LA, dos Santos RM, Gomes Júnior VP, et al. Brazilian guidelines for the management of psychomotor agitation. Part 1. Non-pharmacological approach. Braz J Psychiatry. 2019;41:153-167. http://dx.doi.org/ 10.1590/1516-4446-2018-0163 


\section{Introduction}

An emergency is any situation that is life-threatening and requires immediate intervention. Psychiatric emergencies are changes in behavior that place the patient or others at risk and require immediate therapeutic intervention (within minutes or a few hours) to prevent harm. Among the most prevalent emergencies are suicidal behavior, depressive or manic episodes, self-mutilation, severely impaired judgement, severe self-neglect, intoxication or abstinence, and aggressive psychomotor agitation. ${ }^{1-4}$

Psychomotor agitation is a frequent phenomenon and a clinically relevant condition in patients with psychiatric disorders, not only in urgent situations, but also in hospital or outpatient settings. ${ }^{5}$ Agitation with or without aggressiveness accounts for $2.6-52 \%$ of all psychiatric emergencies worldwide, ${ }^{6-12}$ and for $23.6-23.9 \%(\sim 24 \%)$ of psychiatric emergencies in Brazil. ${ }^{13,14}$

Several guidelines on handling agitation have been produced - such as the Best Practices in Evaluation and Treatment of Agitation, or Project BETA, developed by the American Association for Emergency Psychiatry, ${ }^{15}$ Critical Issues on the Diagnosis and Management of the Adult Psychiatric Patient in the Emergency Department, a clinical policy issued by the American College of Emergency Physicians (ACEP), ${ }^{16}$ Violence - The Short-Term Management of Disturbed/Violent Behavior in Psychiatric In-Patient Settings and Emergency Departments, a 2005 guideline developed by the National Institute for Clinical Excellence (NICE), ${ }^{17}$ and the Assessment and Handling of Agitation in Psychiatry consensus statement. ${ }^{5}$

In Brazil, despite the 2010 article by Mantovani et al. ${ }^{18}$ on the management of violent or agitated patients, to date there are no updated evidence-based guidelines that apply to the reality of this country.

The objective of this study was to develop and present essential recommendations for non-pharmacological management of patients presenting psychomotor agitation in Brazil.

\section{Methods}

This project was developed by a Task Force of 11 Brazilian psychiatrists appointed by the Psychiatric Emergency Committee of the Brazilian Psychiatric Association (Associação Brasileira de Psiquiatria $[A B P])$, based on their experience and knowledge of psychiatric emergencies. To develop these guidelines, the Task Force reviewed 104 articles published from 1997 to 2017 (5,362 articles were screened and 1,731 abstracts were analyzed) retrieved from the MEDLINE (PubMed), Cochrane, and SciELO databases. Other relevant articles identified by searching the reference lists of included studies were also reviewed (Figure 1). The Patient or Population, Intervention or Exposure, Control or Comparison, and Outcome (PICO) model was used to develop the search strategies, as recommended by the Guidelines Project of the Brazilian Medical Association. The use of structured clinical questions was meant to facilitate the design of search strategies. Six sub-themes were selected: environmental and team requirements (what are the environmental and team requirements to manage psychomotor agitation?); minimum assessment (how should a patient presenting psychomotor agitation be assessed?); non-pharmacological approach (how are non-pharmacological approaches used in patients with psychomotor agitation?); physical and other restraint mechanisms (if the pharmacological approach fails, what procedures should be used?).

The following search terms were used: psychomotor agitation plus one among six theme-base keywords (environmental care, team requirements, assessment, nonpharmacological approach, physical restriction, and seclusion). The search was limited to articles published in English, Portuguese, Spanish, or French. Inclusion criteria were age 18 to 65 years; and objective assessment of the response using a scale or reported achievement a calm state. Exclusion criteria were: focus on special groups (i.e., children, delirium), studies including samples with $<20$ participants, case reports, and articles with unclear results.

The articles selected were submitted to the following procedural steps: (i) review of abstracts for selection of relevant articles; (ii) reading all relevant articles in full; (iii) critical analysis of the evidence; (iv) extraction of results and ranking the strength of the evidence. Articles were categorized as systematic reviews, randomized controlled trials, cohort studies, case-control studies, or cross-sectional surveys. Evidence was classified using the Oxford Centre for Evidence-based Medicine ${ }^{19}$ system and critical appraisal tools. ${ }^{19}$ The recommendations were summarized by determining the level of evidence (for more details see https://www.cebm.net/2009/06/oxfordcentre-evidence-based-medicine-levels-evidence-march2009/) and grading of each recommendation as follows: A) consistent level 1 studies; B) consistent level 2 or 3 studies or extrapolations from level 1 studies; C) level 4 studies or extrapolations from level 2 or 3 studies; and D) level 5 evidence or troublingly inconsistent or inconclusive studies of any level.

\section{Results}

\section{Team structure (environmental and team conditions)}

It is important to note that the ideal environment for crisis intervention will not always be available, as emergencies can happen anywhere without warning. In this case, the team should use the resources at hand and follow the general recommendations outlined in the present guidelines, referring the patient to an emergency department as soon as possible. The initial concern must be the safety of the patient and those around him or her.,20 Physicians and other team members must never place themselves in jeopardy (e.g., in a closed room with no easy exit or other compromising situations) (D). ${ }^{5}$

The physical environment is important for managing the agitated patient. A specific physical area should be set aside to handle psychiatric patients, staffed by a dedicated nursing team, with well-ventilated offices and bathrooms on the premises (D). ${ }^{21,22}$ There must be suitable lighting and orientation items such as clocks and calendars to help those who are confused (D). ${ }^{21}$ Facilities must 


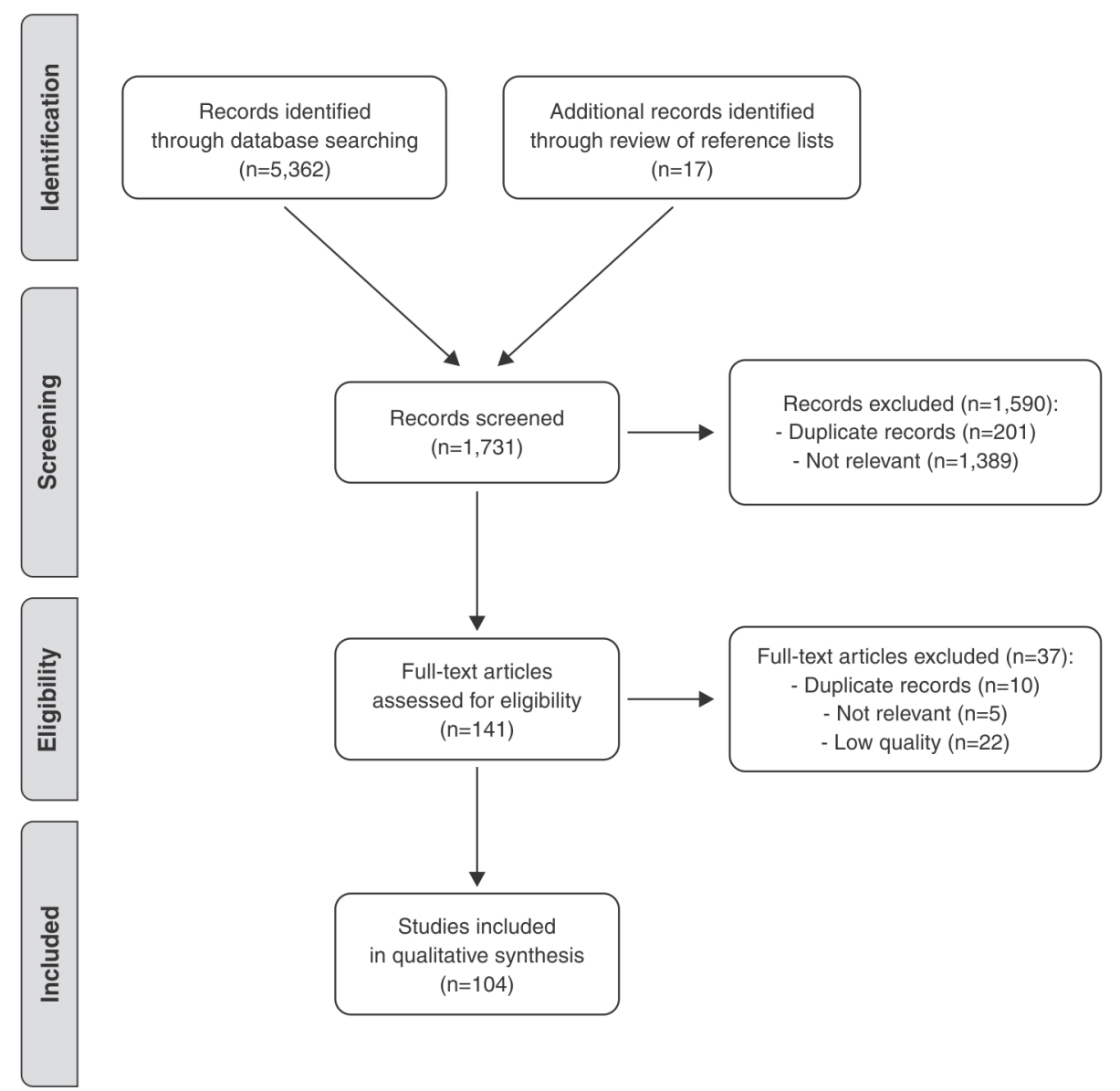

Figure 1 Flowchart for the study selection process.

have suitable climate control - temperature, light, ventilation, and noise (D). ${ }^{22}$

The furniture must be arranged in the waiting room and office so as to provide easy and flexible access to exits for both patients and staff (D). The ability to quickly remove furniture allows a safe environment to be established quickly (D). ${ }^{23}$ Nevertheless, some emergency departments prefer furniture that is secured to floor or walls, so patients cannot use them as weapons, but this may lead to a false sense of safety (D). ${ }^{23}$

Suitable entrance and exit routes must be available and loud sounds, bright colors, and excessive heat or cold eliminated to avoid excess sensory stimulation (D). ${ }^{21-23}$ Patients must be made comfortable, with minimal external stimuli. Rooms should be quiet and individual, and waiting times should be minimized as much as possible (D). ${ }^{5,21,22,24}$

The room set aside for psychiatric urgencies should include a desk and chairs for the patient and family members, an examination table, and a hand-washing sink. $^{4,21,25}$ There must be an exit at the back of the person seeing the patient, which must be completely unobstructed in the event of a threat that cannot be managed (D) ${ }^{4}$ Remember that physicians and staff will be dealing with patients who may be in crisis and could potentially behave unpredictably (D). ${ }^{4}$ Any potentially hazardous items or objects must be removed (D). ${ }^{5}$ Anything that could be used a weapon - such as pens, sharp objects, or table lamps - must be removed or secured (D). ${ }^{23}$ Physicians must keep close tabs on any object that cannot be removed (D). ${ }^{23}$

Often agitation has an organic cause, and these patients may evolve and present complications inherent to their disease or even the treatment. Emergency equipment must be easily available on site (oxygen, manual resuscitators, intubation equipment, secretion aspirator, vaporizer and nebulizer, a crash cart or tray with defibrillator) (D). ${ }^{21}$ The site must be equipped to perform standard and additional lab tests such as capillary blood glucose, blood oxygen and electrocardiography (D). ${ }^{5}$ There should also be physical restraints available, such as wrist, ankle, and chest restraints (D). ${ }^{21}$

Observation areas should be equipped with beds with raised heads and fixed bars for attachment of restraints if necessary. It is inadvisable to keep patients under observation on stretchers $(D) .{ }^{21}$ The layout must be organized to facilitate observation with unobstructed lines of vision and elimination of all blind spots (D). ${ }^{22}$

Occupancy should not exceed the number of beds available, as over-population can increase tension among patients and staff $(D){ }^{22}$ Whenever the team is involved in managing violent behavior, all efforts must be made to manage the patient in a less restrictive physical environment (D). ${ }^{22} \mathrm{~A}$ model that is often used is the psychiatric 
intensive care unit (PICU). ${ }^{22,26}$ This is a small specialized observation unit with suitable space, equipment, safety, and trained team. ${ }^{22,26}$ More favorable results were obtained in patients treated in a PICU vs. a psychiatric acute unit (B). ${ }^{27}$

\section{Characteristics of the team in charge of patients with psychomotor agitation}

The team should be trained and rely on therapeutic protocols outlining all steps in patient care, including the role of each professional in resolving the problem (D). ${ }^{21}$

Acute care settings entail the ability to multitask and tolerate rapidly changing patient priorities. ${ }^{23}$ Physicians working with agitated patients must assess their own aptitude for this work. ${ }^{23}$ Agitated patients may challenge the authority, competence, or credentials of the clinician, and may be very good at detecting and exploring the clinician's vulnerabilities. ${ }^{23}$ Staff members working with agitated patients must recognize and control countertransference issues. ${ }^{23}$ Unless the clinician (and staff) understands his/her own vulnerabilities, behaviors such as retaliating, arguing, or becoming defensive will only serve worsen the situation. Clinicians also need to recognize their limits and learn when to seek additional help (D). ${ }^{23}$

This type of care requires that everyone take on a role. We recommend the use of lab coats, non-provocative attire in neutral colors, and name tags. Staff should avoid dangling earrings, necklaces, or long hair worn loose. The reason for such recommendations is to discourage attacks by more aggressive patient (D) ${ }^{28}$ Suitable distance should be maintained from agitated patients to safeguard the patient and staff. Prolonged direct eye contact and sudden movements may be viewed as a threat, and should be avoided (D). ${ }^{28}$

It is essential that the patient feel respected always. One must judiciously weigh the role of empathetic listener and that of an authority figure, demonstrate knowledge of the topic, and transmit confidence and security to patients and family members (D). ${ }^{28}$ Likewise, provocative and judgmental behavior should be avoided (D). ${ }^{28}$

\section{Assessments}

The arrival of an agitated patient at an emergency department requires quick and effective assessment of the situation to implement the best course of action as soon as possible. The main goals of caring for a patient experiencing psychomotor agitation are: screening and severity assessment; objective and subjective anamnesis; physical and neurological examination; psychiatric examination; differential diagnosis; rapid tranquilization; referral and guidance.

In the case of an agitated patient presenting violent behavior, it may be difficult to perform all these steps as soon as the patient present to the service. Often, the patient must be tranquilized before an assessment can be made.

Because time is important in an emergency, we suggest using four basic questions (D), ${ }^{4}$ as outlined below as well as in Figure 2.
1. What is happening?

List changes in behavior observed that are a cause for concern. Sometimes patients and their families may use too many words or provide information that is not true. It is important to determine the acute changes in behavior that may place the patient or others at risk. It is also important to eliminate any organic causes that may present as psychiatric or behavioral changes.

2. For how long?

Find out if the patient has been displaying these different behaviors for a long or short period of time, and if in fact there was any major, acute change in behavior. Remember that even in the case of patients with a long history of agitation the situation may be urgent. Sudden changes in behavior may also be due to organic factors.

3. Why today?

Find out why they chose that moment to seek emergency help.

4. What are the plausible diagnostic hypotheses or temporary diagnoses?

List diagnostic hypotheses to kick-start the differential diagnosis process and identify the best conduct. In the emergency room, preferably use syndromic diagnoses such as psychotic disorder or mood disorder, as speed will not allow a more detailed diagnosis. Watch for potential causes of agitation.

\section{Triage and severity assessment}

Triage begins on first contact with the agitated patient and involves direct observation and an attempt to establish dialog (D). ${ }^{29}$ The goal is to distinguish patients who require immediate attention from those who can wait their turn or be referred to outpatient care.

In the Beta Project, Nordstrom et al. ${ }^{30}$ suggest using the BARS scale for triage and decision-making in nonmedical settings. Basically, patients with reduced levels of consciousness who are not responsive or cannot be roused should be referred to a medical emergency department immediately. Drowsy patients who respond normally to verbal or physical contact, drowsy patients who appear sedated, or violent patients requiring physical restraint should be sent to a medical emergency unit or to a psychiatric emergency service with ambulance support (D). For patients showing signs of agitation who do not require physical restraints, or if they calm down when instructed, attempts should be made to use a verbal approach to reduce agitation (verbal de-escalation technique). If this fails, the patient should be referred to an emergency department (D). ${ }^{30}$

Only patients who calm down and/or respond to verbal instructions should be kept in waiting rooms. All others should be immediately treated in emergency services (D). In some situations, in both emergency and non-emergency settings (D), ${ }^{30}$ agitation may be considered more severe and indicate behavioral changes secondary to physical illnesses. These situations are listed in Box 1.

Patients arriving at an emergency unit must be assessed by a psychiatrist or nurse to establish the patient's will and ability to engage in conversation and to gather data about 

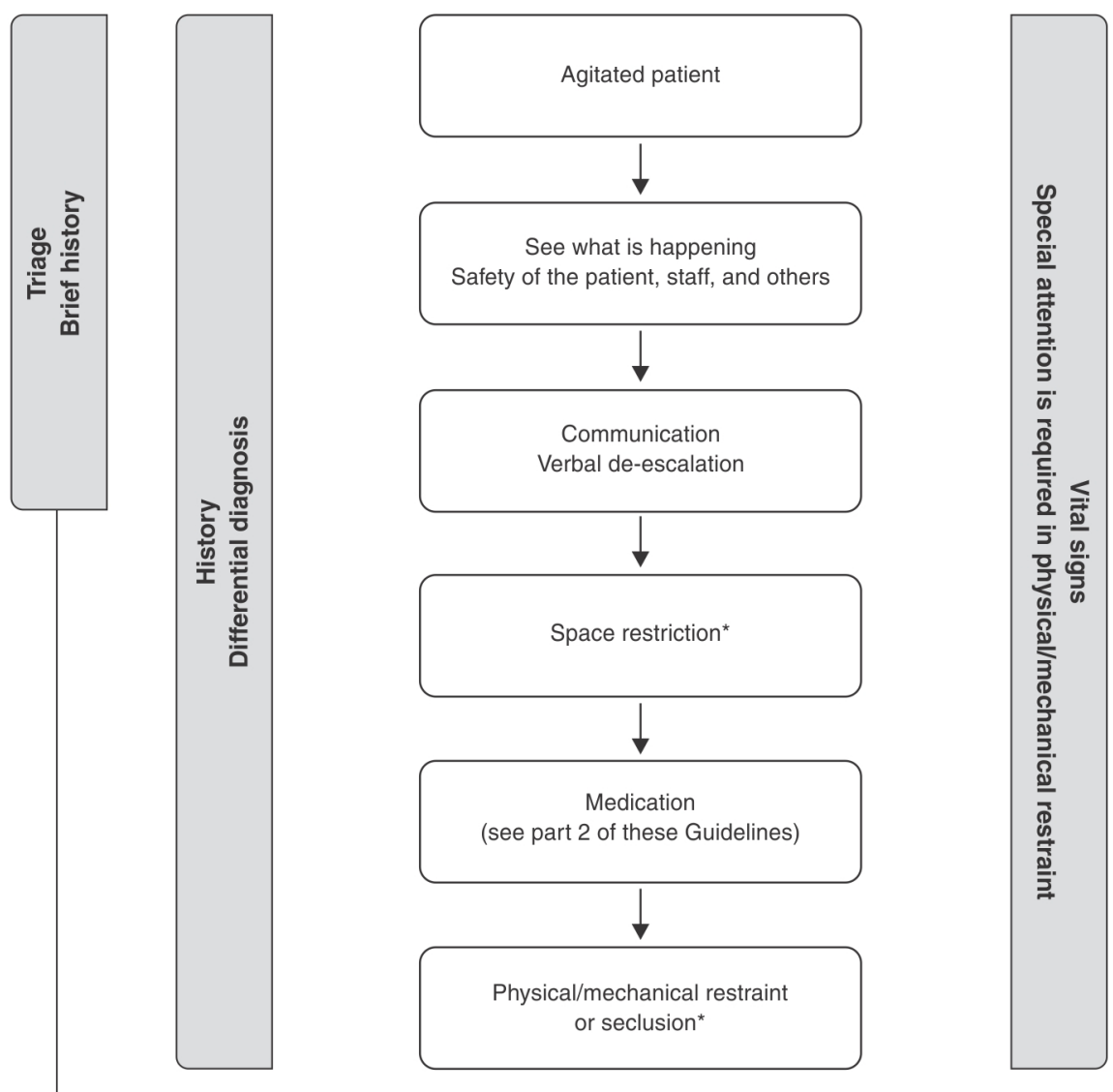

1. What is happening?

List changes in behavior observed that are a cause for concern. Sometimes patients and their families may use too many words or provide information that is not true. It is important to determine the acute changes in behavior that may place the patient or others at risk. It is also important to eliminate any organic causes that may present as psychiatric or behavioral changes.

2. For how long?

Find out if the patient has been displaying these different behaviors for a long or short period of time, and if in fact there was any major, acute change in behavior. Remember that even in the case of patients with a long history of agitation the situation may be urgent. Sudden changes in behavior may also be due to organic factors.

3. Why today?

Find out why they chose that moment to seek emergency help.

4. What are the plausible diagnostic hypotheses or temporary diagnoses?

List diagnostic hypotheses to kick-start the differential diagnosis process and identify the best conduct. In the emergency room, preferably use syndromic diagnoses such as psychotic disorder or mood disorder, as speed will not allow a more detailed diagnosis. Watch for potential causes of agitation.

* Little available evidence. Use only if all else fails.

Figure 2 Flow diagram of the management of psychomotor agitation. ${ }^{*}$ Little available evidence. Use only if all else fails.

the patient's previous behavior and treatment (D). ${ }^{32}$ This starts with an interview and a psychiatric examination. Intake procedures provide an opportunity for clinical investigation, with a focus on the less visible symptoms such as negative or cognitive symptoms and investigation of any signs of organic disease (D). ${ }^{32}$ However, because the psychomotor agitation attracts more attention, it may interfere with clinical assessment. ${ }^{32}$ The initial interview must be followed by an examination to determine the best conduct.

The initial triage should include: assessment of patient ability to collaborate based on observation and verbal interaction (wait and dialog); in a pre-emergency environment, assessment of urgency and need for immediate referral to a medical or psychiatric emergency department; in the waiting room, assessment of patient ability to wait and/or level of priority; finally, the staff should gather preliminary data to immediately initiate conduct in the medical office or emergency room. Standardized risk assessments will help ensure the safety of the clinical environment. $^{22}$

1) Assessment of severity. The entire approach, from screening through initial assessment, tranquilization methods, subsequent progress, differential diagnosis, and criteria for discharge and referral must be recorded in the patient's medical record (D). When caring for an agitated patient, vital signs and physical examination, even if simplified, must be performed from time to time (D). 
Box 1 Factors suggesting severe underlying physical disorders in agitated patients ${ }^{30,31}$

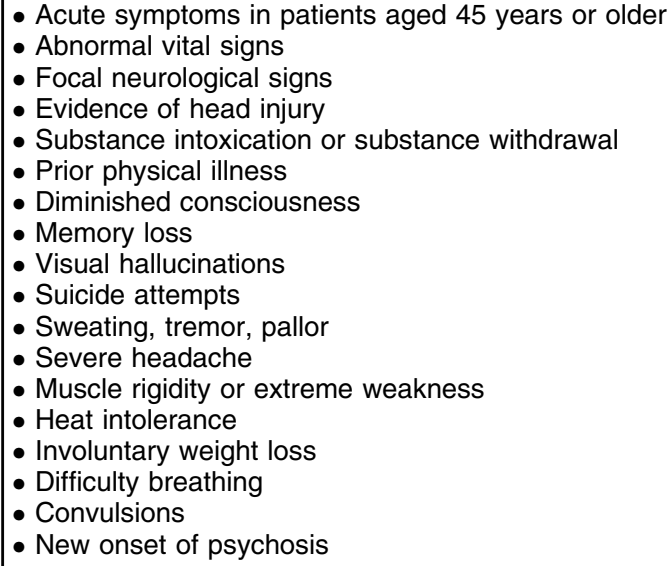

Scales enable assessments that are objective and standard within the team; in addition, they make it possible to effectively monitor approach. The following chart lists the main scales that can be used in such situations. These scales were selected because they have few fields and can be administered in any location. All of them have been used previously for the assessment of agitated patients. Scales that merely assess sedation are not included, nor are long and self-administered scales (it is unlikely that an agitated patient would be able to answer a questionnaire). For scales to assess agitation and violent behavior, see Table 1. We have chosen to select scales that were originally developed in the English language, which can be used by health professionals who are fluent in that language, and have also indicated which ones have been validated for Brazilian Portuguese.

2) Risk of patient becoming aggressive. Agitation is a dynamic situation that may quickly escalate to aggressive or violent behavior. ${ }^{5,51}$ The best conduct for management of aggressive or violent behavior is one that focuses on early identification of individuals at risk of escalating from agitation.

Even though the literature suggests that most of the time violent behavior emerges with no warning, ${ }^{5,52,53}$ some authors suggest that aggressive episodes may be associated with specific risk factors and are preceded by behavioral warning signs, ${ }^{5}$ which are listed in Table 2. Several assessment tools have been designed to assess the risk of aggression/violence, as shown in Table 2.

Factors considered to be protective include harmony among the staff (good working environment) and the presence of male nurses (3A). ${ }^{55}$ Here we would like to stress the importance of a trained and cohesive team with members who respect one another and follow protocols.

\section{Patient history (objective and subjective anamnesis)}

Patient history will be as detailed as the patient is willing or able to disclose. The focus must be the patient, who needs to be heard. The reason for seeking medical help may be different for the patient and his/her companion. Often family members or companions will try to intervene or even purposely irritate the patient. Such practices should be discouraged. Whenever possible, patients should be seen in a quiet environment that makes them and their family members feel safe. It may be acceptable for family members to come into the examining room with or even before the patient to "tell the story," but this may not be productive (D).

If family members insist on remaining in the examining room, they must be instructed not to interfere. In some situations, family members must be asked to leave to allow the conversation to flow (D). The time available for this and the conditions at the psychiatric emergency department may not always be the best. For this reason, patient history should focus on the four questions proposed above (D).

The following information should be obtained: primary complaint, history of current disease, history of mental illness, medical history, substance use and abuse, development, social life, family history, and assessment of mental state. ${ }^{29}$

\section{Physical and neurological examination (D)}

Physical examination is an essential component of the assessment of patients with psychomotor agitation. However, at first it may not be possible to conduct a proper physical. Thus, professionals must be guided by the patient's history and specific signs and symptoms presented. The examination must include at least (D): vital signs (temperature, heart rate, blood pressure, respiratory frequency, oxygen saturation), cardiovascular system, respiratory system, gastrointestinal system, and neurological system. ${ }^{58}$

A complete physical examination may not be possible (e.g., if the patient is uncooperative, confused, violent, or sedated). Nevertheless, a quick observation is always possible and can yield valuable information. Assessment of patient appearance should focus on the following aspects: description (tall, short, thin, obese, gender, age), odor (alcohol, ketone, chemical intoxication, strong body odor), presentation (tidy, disheveled, clean-shaven), scars from previous self-harming (be aware that these scars may be in non-obvious locations such as thighs, stomach or breasts), substance abuse (track marks), medical alert bracelet (epilepsy, diabetes, etc.), obvious signs of injury, affect (e.g., stimulated, agitated, calm), and skin-color (e.g., cyanotic, pale, washed). Minimal neurological assessment should comprise movement of limbs, facial asymmetry, tremor, orientation (patient is aware he/she is in the hospital), level of consciousness (stable of fluctuating), pupils (size, reactivity, equality), and signs of head injury (recent or prior).

\section{Assessment of mental state/psychiatric examination}

There is no single methodology for this assessment. However, the main elements of a minimal psychiatric examination should be covered: presentation, attitude, contact, consciousness, attention, orientation, memory, sensory perception, thoughts, critique (awareness of disease), humor and affect, and psychomotricity (D). ${ }^{59}$ 
Table 1 Scales to assess agitation and aggressiveness/violent state

\begin{tabular}{|c|c|c|}
\hline Scale & Validated in Brazilian Portuguese & Level of evidence \\
\hline Agitation Severity Scale (ASS) ${ }^{33}$ & No & $2 \mathrm{~B}(\mathrm{~B})$ \\
\hline Behavioral Activity Rating Scale (BARS) ${ }^{34}$ & No & $2 B(B)$ \\
\hline Brøset Violence Checklist (BVC) ${ }^{35-37}$ & No & $2 \mathrm{~B}(\mathrm{~B})$ \\
\hline Clinical Global Impression Scale for Aggression (CGI-A) ${ }^{38}$ & No & $2 \mathrm{~B}(\mathrm{~B})$ \\
\hline Historical Clinical Risk Management-20 (HCR-20) ${ }^{39}$ & $\mathrm{Yes}^{40}$ & $2 \mathrm{~B}(\mathrm{~B})$ \\
\hline Overt Aggression Scale (OAS) ${ }^{41}$ & No & $2 \mathrm{~B}(\mathrm{~B})$ \\
\hline Overt Agitation Severity Scale (OASS) ${ }^{42}$ & No & $2 \mathrm{~B}(\mathrm{~B})$ \\
\hline Positive and Negative Syndrome Scale Excited Component ${ }^{43}$ & No & $2 B(B)$ \\
\hline Richmond Agitation-Sedation Scale (RASS) ${ }^{44}$ & Yes $^{45}$ & $2 \mathrm{~B}(\mathrm{~B})$ \\
\hline Sedation-Agitation Scale (SAS) ${ }^{46}$ & $\mathrm{Yes}^{45}$ & $2 \mathrm{~B}(\mathrm{~B})$ \\
\hline Sedation Assessment Tool (SAT) ${ }^{47}$ & No & $1 \mathrm{~B}(\mathrm{~A})$ \\
\hline Staff Observation Aggression Scale-Revised (SOAS-R) ${ }^{48,49}$ & No & $2 B(B)$ \\
\hline Violence Screening Checklist (VSC) ${ }^{50}$ & No & $2 B(B)$ \\
\hline
\end{tabular}

Table 2 Risk factors for aggressiveness/violent behavior

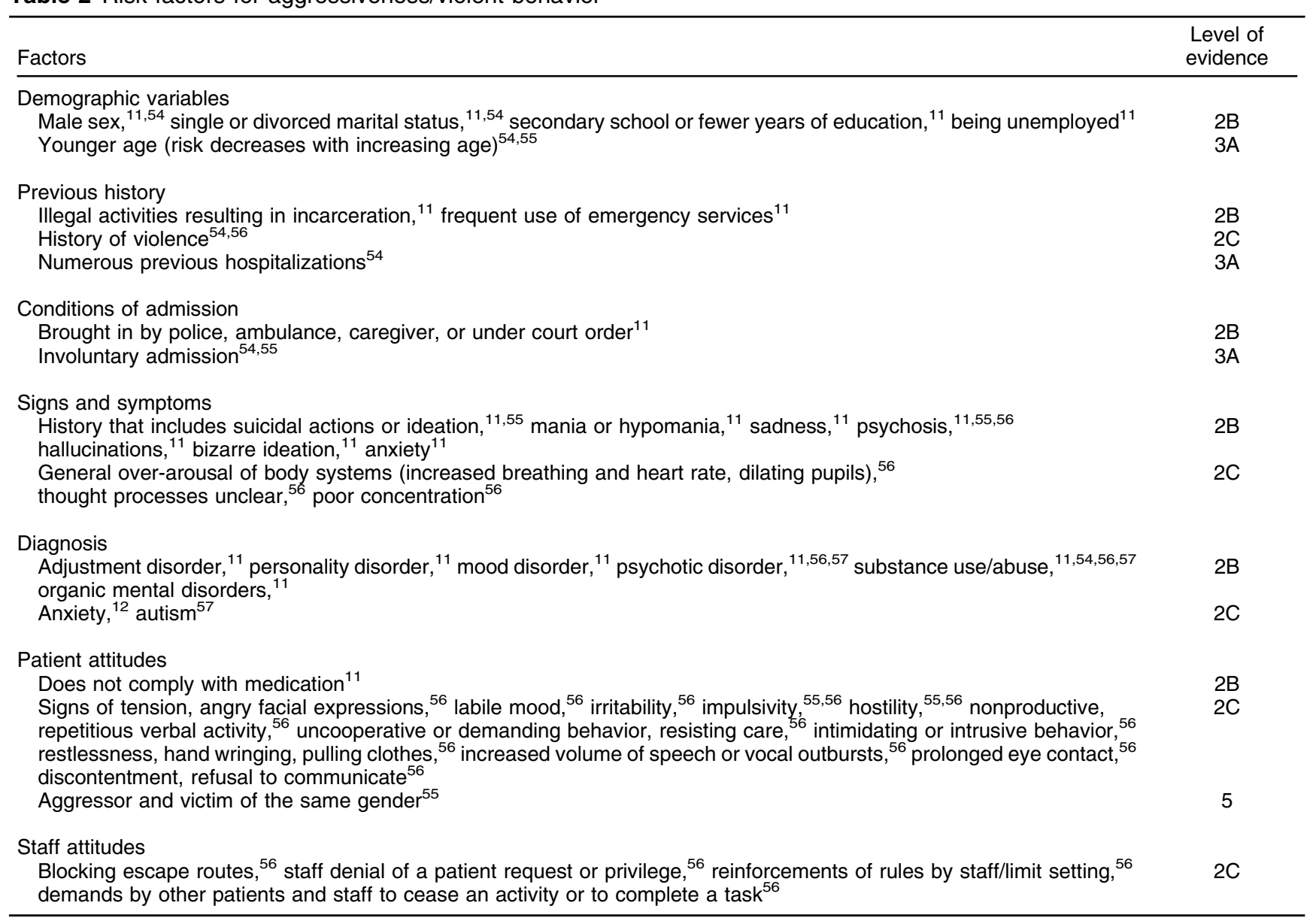

The goal here is not to discuss each of these items. More detail is available in the literature. $4,5,17,18,22,24,25,28,30,31,59$ However, psychiatric functions presenting greater changes should be described in more detail.

\section{Differential diagnosis}

Good clinical reasoning is essential for broad differential diagnosis. Many manifestations, such as psychomotor agitation and aggressiveness, are non-specific and can be associated with several medical conditions. Some clinical data may be indicative of clinical or neurological conditions. These include sudden onset, age over 40 years, no history of psychiatric disorder, visual, olfactory or tactile hallucinations, garbled speech, mental confusion, disorientation, and/or physical signs of trauma. ${ }^{18}$

In an emergency, patients with delirium may be mistakenly diagnosed as being psychotic. The signs of delirium, which include an altered level of awareness, difficulty directing, focusing, sustaining or shifting 
Box 2 Medical and psychiatric conditions that may cause agitation

\begin{tabular}{|l|}
\hline Agitation from general medical condition: \\
Head trauma \\
Encephalitis, meningitis, or other infection \\
Encephalopathy (particularly from liver or renal failure) \\
Exposure to environmental toxins \\
Metabolic derangement (e.g., hyponatremia, hypocalcemia, hypoglycemia) \\
Hypoxia \\
Thyroid disease \\
Seizure (postictal) \\
Toxic levels of medication (e.g., psychiatric or anticonvulsant) \\
Agitation from intoxication/withdrawal \\
Alcohol \\
Other drugs \\
Agitation from psychiatric disorder \\
Psychotic disorder \\
Manic and mixed states \\
Agitated depression \\
Anxiety disorder \\
Personality disorder \\
Reactive or situational agitation (adaptive disorder) \\
Autism spectrum disorder \\
Undifferentiated agitation (presumed to be from a general medical condition until proven otherwise)
\end{tabular}

Adapted from Garriga et al. and Nodstrom et al. ${ }^{5,30}$

attention, may be subtle, and require close attention for detection. ${ }^{29}$

The main medical conditions associated with acute psychomotor agitation are hypoglycemia, hypoxia, traumatic brain injury, hemorrhage, hyperthermia and hypothermia, meningitis, sepsis, stroke, subarachnoid hemorrhage, epileptic state, brain tumors, and thyroid disorders, among others. ${ }^{18}$ The medical and psychiatric conditions that may cause agitation are listed in Box 2 .

A definitive diagnosis is not required following the initial assessment of a patient in the psychiatric emergency department. However, a broader differential diagnosis and classification may be useful for initiating treatment. The main categories are catatonic syndrome, manic syndrome, agitated depressive syndrome, consciousness disorders, psychotic syndrome (delirium, hallucinations), anxiety syndrome, alcohol and/or drug use, and dementia syndrome. ${ }^{5}$

Overdose or abstinence of psychoactive drugs (legal or illegal) may act on the central nervous system and may be involved in behavioral changes such as agitation, aggressiveness, and psychotic syndromes.

Patients with a history of serious psychiatric disorder, such as schizophrenia or bipolar affective disorder, use psychiatric emergency departments often. Manic or psychotic episodes are characterized by disturbed thoughts and altered perception of reality. Periods of psychomotor agitation or aggressiveness may also occur. Depressive episodes may be associated with agitated and aggressive behavior, plus the risk of suicide. Patients with personality disorders may also be found in psychiatric emergency departments, sometimes presenting with agitation or aggressiveness due to impulsivity and low tolerance to frustration. ${ }^{18}$

Psychometric assessments may be useful as an objective record of the differential diagnosis. Scales should be administered case by case and are not covered in these guidelines.
Additional tests

At this point, the decision to order additional tests will help rule out organic causes of the psychic manifestations observed. While there are no lab tests to confirm or rule out psychiatric conditions, tests can be and are widely used to rule out organic pathologies with psychiatric manifestations. ${ }^{5,30,58,60}$ Routine laboratory testing is not indicated; rather, directed testing should be based on the most likely diagnosis. ${ }^{30}$ Workup of agitation from a general medical condition should be directed toward identifying the most likely causes. Table 3 describes the usual tests (D). $., 30,58,60$

Neuroimaging tests should be ordered whenever neurological disease is suspected, and in patients presenting a first psychotic episode (D).

Extra care should be taken if the patient is part of a "special population" - pregnant women, homeless, teens, children, and the elderly. In these populations, care should be taken to exclude organic causes (D).

\section{Rapid tranquilization}

In the presence of psychomotor agitation, with or without aggressiveness, the goal is to protect the patient and those around him or her by adopting attitudes and measures that put the patient at ease. ${ }^{5,61-63}$ Remember that an agitated patient makes a full assessment impossible and complicates the collection of lab specimens.

Preference should be given to less invasive means such as conversation or verbal de-escalation. When none of these options is feasible, medication becomes necessary. In this case, use the concept of rapid tranquilization - calm the patient without excessive (or even no) sedation using fast-acting medication with minimal sideeffects (D). ${ }^{5,18,61-63}$ 
Table 3 Possible additional tests that should be available when caring for agitated patients* (D) ${ }^{60}$

\begin{tabular}{|c|c|c|}
\hline Test & Specimen & Useful for diagnosis of \\
\hline Albumin & Blood & $\begin{array}{l}\text { Nutritional status } \\
\text { Liver disorders }\end{array}$ \\
\hline Amylase, gamma-glutamyl transferase and lipase & Blood & $\begin{array}{l}\text { Pancreatic disease } \\
\text { Bile tract disease } \\
\text { Acute alcohol ingestion }\end{array}$ \\
\hline Aminotransferases & Blood & Liver disease \\
\hline Urinalysis (type I or abnormal elements and sediments) & Urine & $\begin{array}{l}\text { Infections } \\
\text { Metabolic disorders } \\
\text { Urinary stones (calcium?) }\end{array}$ \\
\hline Bilirubin & Blood & Liver disorders \\
\hline Creatine phosphokinase & Blood & $\begin{array}{l}\text { Skeletal muscle damage } \\
\text { Malignant neuroleptic syndrome } \\
\text { Cardiac muscle damage } \\
\text { Central nervous system damage }\end{array}$ \\
\hline Drug serum assay & Blood & $\begin{array}{l}\text { Assessment of toxic levels, } \\
\text { i.e., carbamazepine, valproate and lithium }\end{array}$ \\
\hline Electrocardiogram & Graphic method & ArrhythmiasInfarction \\
\hline Electrolytes & Blood & $\begin{array}{l}\text { Changes in electrolyte levels, } \\
\text { especially as a cause of delirium }\end{array}$ \\
\hline Spinal fluid test & Spinal fluid & $\begin{array}{l}\text { Nervous system infections } \\
\text { Nervous system neoplasmlntracranial hypertension } \\
\text { Demyelinating diseases } \\
\text { Subarachnoid hemorrhage }\end{array}$ \\
\hline Toxicology tests & $\begin{array}{l}\text { Blood } \\
\text { Urine } \\
\text { Saliva } \\
\text { Hair }\end{array}$ & Confirmation of substance abuse \\
\hline Renal function (urea and creatinine) & Blood & $\begin{array}{l}\text { Renal failure due to infections, } \\
\text { kidney stone, poisoning (lithium), } \\
\text { or other diseases }\end{array}$ \\
\hline Thyroid function & Blood & Hypo and hyperthyroidism \\
\hline Glucose & $\begin{array}{l}\text { Blood } \\
\text { Urine }\end{array}$ & $\begin{array}{l}\text { Hyper or hypoglycemia } \\
\text { Differential diagnosis of delirium }\end{array}$ \\
\hline Complete blood count & Blood & $\begin{array}{l}\text { Anemia, leukocytosis or leucopenia, } \\
\text { thrombocytopenia, and thrombocytosis }\end{array}$ \\
\hline Neural imaging (brain CT scan or MRI) & Image & $\begin{array}{l}\text { Differential diagnosis of delirium and other organic } \\
\text { mental disordersBrain neoplasmStrokeCentral nervous } \\
\text { system infections }\end{array}$ \\
\hline Chest X-ray & Image & $\begin{array}{l}\text { Lung disease } \\
\text { Heart disease }\end{array}$ \\
\hline Serum tests & Blood & Infectious diseases \\
\hline Prothrombin time & Blood & $\begin{array}{l}\text { Coagulation disorders } \\
\text { Liver disorders }\end{array}$ \\
\hline Pregnancy test & $\begin{array}{l}\text { Blood } \\
\text { Urine }\end{array}$ & Pregnancy \\
\hline Vitamin B12 and folate & Blood & Megaloblastic anemia \\
\hline
\end{tabular}

$\mathrm{CT}$ = computerized tomography; $\mathrm{MRI}=$ magnetic resonance imaging.

* Tests must be requested based on clinical assessment. 


\section{Referral and guidance}

Once the patient is calm, a decision can be made as to whether she or he should be referred for outpatient care or remain in the emergency room for observation or admission. Far more important than the diagnosis itself is an assessment of the risk the patient poses to himself and others, and of his/her ability for self-care (D). It is important to dedicate time to assessment as a considerable share of these patients do not follow the instructions they receive, and do not comply with the prescribed medication. There is a greater chance for success if the instructions are shared with the family (D).

\section{Interviewer position, attitude, and verbal approach}

When interacting with an agitated patient it is important to keep your distance and respect the patient's personal space (D). ${ }^{5}$ Patients may understand prolonged or intense direct eye-contact as a threat (D). ${ }^{5}$ Body language and position can also be considered threatening or conflicting (e.g., keeping your arms crossed or your hands hidden behind your back) (D). ${ }^{5}$ We recommend that agitated patients not be interviewed by a single professional (D) ${ }^{5,64,65}$ Other recommendations are to minimize patient waiting time, adopt a confident, respectful, and attentive attitude, and approach the patient carefully (D). ${ }^{5,24}$

The first therapeutic intervention with an agitated patient is normally verbal and based on empathic dialogue. The team must demonstrate it is fully invested in the patient's well-being and make sure he or she is protected from harm. The goal is to establish a good relationship between staff and patient, based on trust and respect, so the patient will feel welcome and believe his/her suffering is recognized. This will help establish a joint effort to control aggressiveness.

Patients presenting psychomotor agitation may emotionally impact the physician, who may feel threatened, or believe there is a threat to other patients under their care or to the staff. Feelings of fear or anger are to be expected in threatening situations. Physicians must be aware of their own feelings and determine the extent to which they reflect the actual situation and be aware that threatening and hostile behavior are the clinical manifestation of a mental disorder. This is essential if the physician is to remain neutral and take measures that are not overly permissive or punitive.

Some initial recommendations of relatively simple attitudes and behaviors can be a major help in managing agitated patients. Physicians must introduce themselves to the patient by stating their name and their role in the situation. They should always be available to see the patient and explain what is being done. Pay close attention to what the patient is saying and doing. Never turn your back on an agitated patient. Use simple words and short sentences. Speak slowly but firmly, and avoid a tone or words that sound hostile or overly authoritarian. Verbal interventions should be clear and objective. While one should not bargain with the patient, some flexibility must be maintained during the interview, and attention paid to what the patient is saying or wants. Move slowly and keep a certain distance from the patient. This will prevent patient attacks on the physician and will make the patient feel calmer. Depending on the psychotic symptoms, physical contact may be perceived as threatening.

Limits regarding the risk of physical harm and rules in the service must be stated clearly and objectively from the start, without threat or humiliation. This is not the time for confrontation. Patients must be encouraged to express their thoughts in words, and physicians must stress the patient's ability for self-control. Maintain eye contact and try to avoid taking notes.

If verbal intervention is not enough and agitation worsens, containment measures must be taken immediately to protect the patient and others and preserve a positive interpersonal relationship.

An agitated patient who is still in control may respond favorably to a verbal intervention. However, an agitated patient in the middle of a psychotic event may require physical and then pharmacological containment.

Verbal de-escalation was initially defined by Stevenson \& Otto ${ }^{66}$ as "talking-down" the patient. They described verbal de-escalation as a complex interactive process in which the patient is guided to a more peaceful personal space. $^{5,66}$ The ability of verbal de-escalation to reduce agitation and reduce the risk that the situation will evolve to violence has been demonstrated. However, while much has been written about pharmacological approaches in agitated patients, there is little evidence on the effectiveness of verbal techniques. ${ }^{23}$ Allen et al. ${ }^{67}$ recommend verbal intervention or voluntary medication (i.e., administered with the consent of the patient) before switching to more intrusive strategies (D).

More recently, project BETA has proposed 10 domains of verbal de-escalation techniques for the management of the agitated patient. ${ }^{23}$ The authors considered noncoercive de-escalation techniques as the intervention of choice in the management of acute agitation in order to calm the agitated patient by gaining his/her cooperation. ${ }^{5,68}$ We recommend reading and training based on project BETA recommendations. ${ }^{23}$ The general principles of verbal de-escalation are $\left.{ }^{5,23}: 1\right)$ respect the patient and his/her personal space; 2) do not be provocative; 3) establish verbal contact; 4) be concise; 5) identify desires and feelings; 6 ) listen closely to what the patient is saying; 7) agree or agree to disagree; 8) have clear rules and limits; 9) offer options and optimism; and 10) debrief patient and staff.

\section{Physical restraint}

Physical restraint is defined as any physical or mechanical means, material, or equipment attached to the patient's body to contain it and that cannot be easily removed. ${ }^{5,68-70}$ These devices limit the person's movement, with the primary function of protecting the patient from his/her own agitated behavior. ${ }^{69,70}$

Physical restraint is a practice employed in psychiatric emergencies. It is a useful method for preventing injury and reducing agitation. The literature suggests that it is almost impossible to run a program for seriously ill individuals without the use of restraint. ${ }^{68,71}$ Physical restraints are 
used in 3.8-26\% of all mental disorders seen in hospital. ${ }^{72-86}$ There is inconclusive evidence regarding the difference in incidence between the sexes. Some studies show a higher incidence of physical restraints in male patients, ${ }^{80,85}$ while others report higher incidence in females. ${ }^{87,88}$

Restraints are normally used in individuals with a diagnosis of psychosis, substance use or abuse, mood disorders, personality disorders, such as anti-social and borderline personality disorders, mania episodes, and comorbidity between psychosis and substance abuse (evidence 2C). ${ }^{85-87,89-92}$

The more serious the agitation, the greater the chance that restraints will be used. ${ }^{85,93}$ Other factors related to the risk of containment are: younger age, ${ }^{74,87,90,91,94}$ anguish by confinement, ${ }^{91,95}$ feeling of victimization and humiliation, ${ }^{91,95}$ lack of clear rules, ${ }^{83,91,95}$ history of violence, ${ }^{92}$ violent patients, ${ }^{91,96}$ ethnic minority, ${ }^{91,94}$ immigrants, ${ }^{74,91}$ attempted escape, ${ }^{91,96}$ use of a specially closed isolation room, ${ }^{91,97}$ nursing as a target of violence, ${ }^{91,98}$ male nurses, ${ }^{91}$ self-assaults and suicidal behavior, ${ }^{91,99}$ and hostility at admission ${ }^{91,100}$ (level of evidence 2C).

\section{Indications}

The main indication is failure of other non-invasive techniques to calm the patient, such as a verbal approach and contained space. ${ }^{88,101}$ The psychiatric conditions that normally lead to the use of physical restraint are psychomotor agitation, mental confusion and aggressiveness or violence to self, objects and/or others, unresponsiveness to less invasive interventions, risk of falls and suicidal behavior, and high risk of patient flight (D). Clinical indications are immobilization to keep the patient from falling after sedation or in the case of mental confusion; certain tests or treatments; patients who are non-cooperative to keep catheters, drains or dressings in place, among others. (D).

\section{Safety and efficacy (2B)}

Even though experts agree regarding the indications for the use of physical restraint, there is limited empirical evidence supporting the safety and effectiveness of this measure. As a rule, restraint is only used where other measures fail. ${ }^{5,22,68}$ It is also important to stress that there are methodological and ethical limitations to conducting clinical trials on this type of intervention, as the indications are variable, and one cannot fail to restrain a patient where restraint is clearly indicated merely for comparison purposes. However, one clinical trial compared the efficacy of physical restraint and isolation and found no difference, except that one-third of the isolation patients had to be moved to physical restraints, which suggests that restraint is more appropriate for agitated patients $(\mathrm{B}) .^{88}$

However, physical restraint involves significant psychological and physical risk. ${ }^{68,102}$ The trauma of such coercive measures may lead to feelings of fear, humiliation, and impotence for both the patient and staff. ${ }^{68,102}$ There may be physical complications such as orthopedic injury, dehydration, rhabdomyolysis, thrombosis, asphyxia, and even death. ${ }^{6,71,102,103}$ To reduce fatalities, physical restraints should only be used as a last resource, and only by people who are well trained in managing psychomotor agitation.

\section{Technique}

A recent study in Brazil found that the most commonly used restraint is the so-called four-point method (47.8\%), and that many patients were restrained for longer than 240 minutes (27.3\%). ${ }^{104}$ Complete vital signs were recorded in three points in time in only $40.8 \%$ of the cases immediately after being restrained, 30 minutes after that, and when restraints are removed. ${ }^{104}$ Regarding adverse events, $56.2 \%$ of the patients had none; no information regarding adverse events was recorded in $42.6 \%$ of the patients. Only $0.4 \%$ of the patients presented dehydration as an adverse event. ${ }^{104}$

The main recommendations for restraining patients are listed below.

1. Physical intervention/restraint should only be considered once all de-escalation techniques have failed. ${ }^{5,22,68}$

2. Services must identify and promote best practices in the prevention, reduction, and where possible elimination of physical intervention/restraint. ${ }^{22}$

3. If physical intervention is unavoidable, then it must not be used for prolonged periods, and must be terminated at the earliest opportunity. ${ }^{22}$

4. The dignity of patients must be respected during physical intervention, and the reasons for using the intervention must explained as much as possible..$^{22}$

5. All staff involved in physical intervention/restraint should be trained in a standardized technique. ${ }^{22}$

6. The physician or other staff must inform the patient, his/ her family, and/or companions of the need for physical restraints.

7. Restraints are used only with a medical prescription and for a finite period, in principle no longer than 2 hours.

8. The procedure is performed by the care staff (five members, but two more may be necessary in some cases) with each professional taking responsibility for one single limb. Whoever oversees the restraining procedure is responsible for protecting the patient's head and airways, and for checking vital signs throughout the procedure.

9. The following restraint mechanisms may be used (D):

- 4-point: forearms and ankles or, in other words, at the end of all four limbs with the patient lying down in bed (avoid restraints on stretchers), with the head raised and the upper limbs alongside the torso. Avoid cutting off blood flow to the extremities.

- 5-point: the end of the limbs plus the chest. For chest restraint, a sheet or sash may be used. Restraints should be placed perpendicularly over the trunk. Do not place restraints under armpits, as this can harm the branchial plexus. In women, be careful with the breasts, using a sash that is wide enough to cover them, or place the sash immediately below the breasts.

- 9-point: in the event of severe agitation, where all other techniques have failed, place restraints at the end of all four limbs, the arms, thighs and chest. 
- Other options: abdominal restraints for severely agitated patients where chest restraints may not be used or to avoid motion (e.g., following surgery). However, care must be taken not to compress the operated region. Knee containment is an alternative to containing thighs. Hand containment (so patients cannot remove catheter or self-harm) can be done with commercially available gloves or by placing cotton on the inside of the hands and then binding it so that all fingers are covered.

10. Monitoring of vital signs, blood flow, and the restraint site (pain, heat, swelling or wound) should begin soon as restraints are placed, and then performed every 15 minutes for 60 minutes, and then every 30 minutes for 4 hours or until the patient awakens. ${ }^{5,22}$ Record the entire procedure in the patient's chart, including justification and monitoring.

\section{Types of material}

The simplest and least expensive restraints are fabric sashes, preferably soft, and comfortable on the skin, but resistant (D). We do not recommend the use of bandages or any device used by police authorities, such as handcuffs (D). Restraints made of leather, fabric, or canvas can also be used, as long as they are comfortable and do not harm the patient.

\section{Seclusion (evidence level 2B)}

Seclusion is involuntary confinement in a special room ${ }^{5,68}$ that may be locked or unlocked. In general, confinement rooms are devoid of furniture. In theory, seclusion is less restrictive than mechanical restraints. Most hospitals in Brazil no longer use seclusion rooms. ${ }^{68}$ The absence of efficacy studies to date limits our knowledge of the benefits of seclusion as a treatment. One clinical trial compared restraints and seclusion and concluded that, while complications are possible, the method is effective. However, one-third of the people from the seclusion group had to be transferred into a more coercive form of restriction, the great majority because of swift deterioration in behavior. ${ }^{88}$ The Consensus Statement of the American Association for Emergency Psychiatry Project BETA Seclusion and Restraint Workgroup ${ }^{68}$ suggests that, if the patient is not a danger to others, seclusion should be considered. However, if the patient could be a danger to himself while in seclusion, restraint is appropriate. Despite the evidence, however, in the absence of other studies corroborating the efficacy of seclusion, we recommend avoiding this method.

Finally, seclusion and restraint must be discontinued at the earliest possible time ${ }^{68}$ and, as any other technique, must be monitored and supervised at regular intervals. ${ }^{68}$

\section{Limitations}

Most of the articles identified (except for the validations of scales) are reviews, consensus statements or crosssectional studies. There is a lack of clinical trials on the subject, which suggests a field for new research. Therefore, the present guidelines must periodically be updated.

\section{Conclusion}

There is still little evidence in the literature regarding the non-pharmacological approach to psychomotor agitation; however, it is possible to systematize the information that is currently available. The care of the agitated patient begins with a verbal approach. If the event unfolds outside a health care facility, the patient must be directed to an appropriate location for assessment and further management. It is important that healthcare professionals be trained in non-pharmacological approaches a part of the requirements for a degree and graduate degree. All healthcare teams must be trained to address difficulties and improve the technique to ensure a favorable outcome. Verbal de-escalation techniques have the potential to decrease agitation and reduce the likelihood of violence in the emergency setting. The possibility of underlying medical etiologies must be considered first and foremost. Particular attention should be paid to the patient's appearance and behavior, physical signs, and mental state. It is also very important to point out that the approach of an agitated patient must always start with the least less coercive measure. Conversely, if agitation is severe, pharmacological measures should be taken (for more details see Part 2 of these Guidelines, on pharmacological approach ${ }^{105}$ ). Finally, if all measures fail, physical restraint should be used for patient protection, and always be accompanied by rapid tranquilization. Figure 2 shows the proposed the hierarchical sequence for the management of psychomotor agitation.

\section{Acknowledgements}

The authors wish to thank the Brazilian Psychiatric Association $(\mathrm{ABP})$ for providing physical space and time during events for team meetings.

\section{Disclosure}

LB has served as consultant for Apsen and participated in a meeting from Libbs. LAP has served as speaker for Janssen-Cilag, Servier, EMS, and Libbs. LAP has received support to participate in meetings from JanssenCilag, Lundbeck, Abbott, Servier, and Libbs. CAM has served as speaker for Lundebeck and has performed research for Janssen-Cilag. TCT has served as member of the advisory board/consultant for Aché, Abbott, Servier, Lundbeck, and Apsen; has served as speaker for Aché, Abbott, Pfizer, EMS, Medley/Sanofi, Lundbeck, Servier, Libbs, Apsen, Torrent, and Daichii-Sankyo; has performed research for Janssen-Cilag and served as consultant for clinical/scientific related promotional articles for Aché, Abbott, Pfizer, EMS, Medley/Sanofi, Lundbeck, Servier, Supera, Janssen-Cilag, Cristália, Libbs, Apsen, Torrent, and Daichii-Sankyo. QC works in the Ministry of Health and is responsible for the elaboration of public policies in mental health in Brazil. The other authors report no conflicts of interest. 


\section{References}

1 Calfat ELB. Apresentação do pronto-socorro do centro de atenção integrada à saúde mental da irmandade da Santa Casa de Misericórdia de São Paulo. In: Cordeiro DC, Baldacara L. Emergências psiquiátricas.São Paulo: Roca; 2007. p. 1-9.

2 Barros RE, Marques JM, Carlotti IP, Zuardi AW, Del-Ben CM. Short admission in an emergency psychiatry unit can prevent prolonged lengths of stay in a psychiatric institution. Rev Bras Psiquiatr. 2010; 32:145-51.

3 Cruz CM, Leiva JL, Borgoño RV, Larach TK, Errázuriz LB, Chianale IC, et al. Epidemiología de la Urgencia Psiquiátrica en el Instituto Psiquiátrico "Dr. José Horwitz": Un nuevo estudio comparativo. Rev Chilena Neuro-Psiquiatr. 2010;48:175-83.

4 Quevedo J, Carvalho AF. Emergências psiquiátricas. 2a ed. Porto Alegre: Artmed; 2014.

5 Garriga M, Pacchiarotti I, Kasper S, Zeller SL, Allen MH, Vázquez G, et al. Assessment and management of agitation in psychiatry: Expert consensus. World J Biol Psychiatry. 2016;17:86-128.

6 Pascual JC, Madre M, Puigdemont D, Oller S, Corripio I, Díaz A, et al. [A naturalistic study: 100 consecutive episodes of acute agitation in a psychiatric emergency department]. Actas Esp Psiquiatr. 2006;34:239-44.

7 Boudreaux ED, Allen MH, Claassen C, Currier GW, Bertman L, Glick R, et al. The Psychiatric Emergency Research Collaboration01: methods and results. Gen Hosp Psychiatry. 2009;31:515-22.

8 Pajonk FG, Schmitt P, Biedler A, Richter JC, Meyer W, Luiz T, et al. Psychiatric emergencies in prehospital emergency medical systems: a prospective comparison of two urban settings. Gen Hosp Psychiatry. 2008;30:360-6.

9 San L, Marksteiner J, Zwanzger P, Figuero MA, Romero FT, Kyropoulos G, et al. State of Acute Agitation at Psychiatric Emergencies in Europe: The STAGE Study. Clin Pract Epidemiol Ment Health. 2016;12:75-86.

10 Brakoulias V, Mandali R, Seymour J, Sammut P, Starcevic V. Characteristics of admissions to a recently opened Psychiatric Emergency Care Centre. Australas Psychiatry. 2010;18:326-9.

11 Chaput Y, Beaulieu L, Paradis M, Labonte E. Aggressive behaviors in the psychiatric emergency service. Open Access Emerg Med 2011;3:13-20.

12 Grudnikoff E, Taneli T, Correll CU. Characteristics and disposition of youth referred from schools for emergency psychiatric evaluation. Eur Child Adolesc Psychiatry. 2015;24:731-43.

13 Santos ME, do Amor JA, Del-Ben CM, Zuardi AW. [Psychiatric emergency service in a university general hospital: a prospective study]. Rev Saude Publica. 2000;34:468-74.

14 Padilha VM, Schettini CS, Santos Junior A, Azevedo RC. Profile of patients attended as psychiatric emergencies at a university general hospital. Sao Paulo Med J. 2013;131:398-404.

15 Holloman GH Jr., Zeller SL. Overview of Project BETA: Best practices in Evaluation and Treatment of Agitation. West J Emerg Med. 2012;13:1-2.

16 Lukens TW, Wolf SJ, Edlow JA, Shahabuddin S, Allen MH, Currier $\mathrm{GW}$, et al. Clinical policy: critical issues in the diagnosis and management of the adult psychiatric patient in the emergency department. Ann Emerg Med. 2006;47:79-99.

17 National Institute for Clinical Excellence (NICE). Violence: the shortterm management of disturbed/ violent behaviour in psychiatric inpatient settings and emergency departments [Internet]. London: NICE; 2005 [cited 2018 Apr 17]. https://www.rcpsych.ac.uk/PDF/ NICE\%20Guideline\%202005.pdf

18 Mantovani C, Migon MN, Alheira FV, Del-Ben CM. Manejo de paciente agitado ou agressivo. Rev Bras Psiquiatr. 2010;32:S96S103.

19 Centre for Evidence-based Medicine (CEBM). Oxford Centre for Evidence-based Medicine - Levels of Evidence (March 2009) [Internet] Oxford: CEBM; 2009 [cited 2018 Apr 17]. http://www.cebm.net/oxfordcentre-evidence-based-medicine-levels-evidence-march-2009/

20 Schleifer JJ. Management of acute agitation in psychosis: an evidence-based approach in the USA. Adv Psychiatr Treat. 2011; 17:91-100.

21 Kawakami D, Prates JG, Tung TC. Propostas para o futuro: estrutura física e equipe ideal nas emergências psiquiátricas. Rev Debates Psiquiatr. 2016;6:28-34.
22 Government of Western Australia, Department of Health. The management of disturbed/violent behaviour in inpatient psychiatric settings. East Pearth: Government of Western Australia, Department of Health; 2006.

23 Richmond JS, Berlin JS, Fishkind AB, Holloman GH Jr, Zeller SL, Wilson MP, et al. Verbal De-escalation of the Agitated Patient: Consensus Statement of the American Association for Emergency Psychiatry Project BETA De-escalation Workgroup. West J Emerg Med. 2012;13:17-25.

24 Marder SR. A review of agitation in mental illness: treatment guidelines and current therapies. J Clin Psychiatry. 2006;67(Suppl 10):13-21.

25 Caldieraro MA, Spode A, Fleck MPA. Avaliação do paciente na emergência. In: Quevedo J, Schimitt R, Kapczinski F. Emergências psiquiátricas. Porto Alegre: Artmed; 2008. p. 17-48.

26 O'Brien L, Cole R. Close-observation areas in acute psychiatric units: a literature review. Int J Ment Health Nurs. 2003;12:165-76.

27 Vaaler AE, Morken G, Fløvig JC, Iversen VC, Linaker OM. Effects of a psychiatric intensive care unit in an acute psychiatric department. Nord J Psychiatry. 2006;60:144-9.

28 Baldaçara L, Cordeiro DC, Calfat ELB, Cordeiro Q, Tung TC Emergências psiquiátricas. $2^{\mathrm{a}}$ ed. Rio de Janeiro: Elsevier; 2018.

29 Stowell KR, Florence P, Harman HJ, Glick RL. Psychiatric evaluation of the agitated patient: consensus statement of the American association for emergency psychiatry project Beta psychiatric evaluation workgroup. West J Emerg Med. 2012;13:11-6.

30 Nordstrom K, Zun LS, Wilson MP, Md VS, Ng AT, Bregman B, et al. Medical evaluation and triage of the agitated patient: consensus statement of the American association for emergency psychiatry project Beta medical evaluation workgroup. West J Emerg Med. 2012;13:3-10.

31 Government of Western Australia, Department of Health. Guidelines: The management of disturbed/violent behaviour in inpatient psychiatric settings. Mental Health Division, Department of Health, Government of Western Australia; 2006.

32 Passamar M, Tellier O, Vilamotc B. L'agitation psychomotrice, la sédation médicamenteuse et l'urgence psychiatrique chez le patient psychotique. L'Encéphale. 2011;37:448-56.

33 Strout TD. Psychometric testing of the Agitation Severity Scale for acute presentation behavioral management patients in the emergency department. Adv Emerg Nurs J. 2014;36:250-70.

34 Swift RH, Harrigan EP, Cappelleri JC, Kramer D, Chandler LP. Validation of the behavioural activity rating scale (BARS): a novel measure of activity in agitated patients. J Psychiatr Res. 2002;36: 87-95.

35 Almvik R, Woods P. Predicting inpatient violence using the Broset Violence Checklist (BVC). Int J Psychiatr Nurs Res. 1999;4:498-505.

36 Abderhalden C, Needham I, Miserez B, Almvik R, Dassen T, Haug $\mathrm{HJ}$, et al. Predicting inpatient violence in acute psychiatric wards using the Broset-Violence-Checklist: a multicentre prospective cohort study. J Psychiatr Ment Health Nurs. 2004;11:422-7.

37 Abderhalden C, Needham I, Dassen T, Halfens R, Haug HJ, Fischer J. Predicting inpatient violence using an extended version of the Broset-Violence-Checklist: instrument development and clinical application. BMC Psychiatry. 2006;6:17.

38 Huber CG, Lambert M, Naber D, Schacht A, Hundemer HP, Wagner TT, et al. Validation of a Clinical Global Impression Scale for Aggression (CGI-A) in a sample of 558 psychiatric patients. Schizophr Res. 2008;100:342-8.

39 Douglas KS, Ogloff JR, Nicholls TL, Grant I. Assessing risk for violence among psychiatric patients: the HCR-20 violence risk assessment scheme and the Psychopathy Checklist: Screening Version. J Consult Clin Psychol. 1999;67:917-30.

40 Telles LE, Day VP, Folino JO, Taborda JG. Reliability of the Brazilian version of HCR-20 Assessing Risk for Violence. Rev Bras Psiquiatr. 2009;31:253-6.

41 Yudofsky SC, Silver JM, Jackson W, Endicott J, Williams D. The Overt Aggression Scale for the objective rating of verbal and physical aggression. Am J Psychiatry. 1986;143:35-9.

42 Yudofsky SC, Kopecky HJ, Kunik M, Silver JM, Endicott J. The Overt Agitation Severity Scale for the objective rating of agitation. J Neuropsychiatry Clin Neurosci. 1997;9:541-8.

43 Montoya A, Valladares A, Lizan L, San L, Escobar R, Paz S. Validation of the Excited Component of the Positive and Negative 
Syndrome Scale (PANSS-EC) in a naturalistic sample of 278 patients with acute psychosis and agitation in a psychiatric emergency room. Health Qual Life Outcomes. 2011;9:18.

44 Sessler CN, Gosnell MS, Grap MJ, Brophy GM, O'Neal PV, Keane KA, et al. The Richmond Agitation-Sedation Scale: validity and reliability in adult intensive care unit patients. Am J Respir Crit Care Med. 2002;166:1338-44.

45 Nassar Junior AP, Pires Neto RC, de Figueiredo WB, Park M. Validity, reliability and applicability of Portuguese versions of sedation-agitation scales among critically ill patients. Sao Paulo Med J. 2008; $126: 215-9$

46 Ryder-Lewis MC, Nelson KM. Reliability of the Sedation-Agitation Scale between nurses and doctors. Intensive Crit Care Nurs. 2008;24:211-7.

47 Calver LA, Stokes B, Isbister GK. Sedation assessment tool to score acute behavioural disturbance in the emergency department. Emerg Med Australas. 2011;23:732-40.

48 Hvidhjelm J, Sestoft D, Bjørner JB. The Aggression Observation Short Form identified episodes not reported on the Staff Observation Aggression Scale--Revised. Issues Ment Health Nurs. 2014;35:464-9.

49 Nijman HLI, Muris P, Merckelbach HLGJ, Palmstierna T, Wistedt B, Vos AM, et al. The Staff Observation Aggression Scale--Revised (SOAS-R). Aggress Behav. 1999;25:197-209.

50 McNiel DE, Gregory AL, Lam JN, Binder RL, Sullivan GR. Utility of decision support tools for assessing acute risk of violence. J Consult Clin Psychol. 2003;71:945-53.

51 Citrome L, Volavka J. The psychopharmacology of violence: making sensible decisions. CNS Spectr. 2014;19:411-8.

52 Duxbury J, Whittington R. Causes and management of patient aggression and violence: staff and patient perspectives. J Adv Nurs. 2005;50:469-78.

53 Buchanan A, Leese M. Detention of people with dangerous severe personality disorders: a systematic review. Lancet. 2001;358:1955-9.

54 Dack C, Ross J, Papadopoulos C, Stewart D, Bowers L. A review and meta-analysis of the patient factors associated with psychiatric in-patient aggression. Acta Psychiatr Scand. 2013;127:255-68.

55 Cornaggia CM, Beghi M, Pavone F, Barale F. Aggression in psychiatry wards: a systematic review. Psychiatry Res. 2011;189:10-20.

56 Hankin CS, Bronstone A, Koran LM. Agitation in the inpatient psychiatric setting: a review of clinical presentation, burden, and treatment. J Psychiatr Pract. 2011;17:170-85.

57 Långstrøm N, Grann M, Ruchkin V, Sjøstedt G, Fazel S. Risk factors for violent offending in autism spectrum disorder: a national study of hospitalized individuals. J Interpers Violence. 2009:24:1358-70.

58 The New South Wales Department of Health. Mental Health and Drug and Alcohol Office, Mental Health for Emergency Departments A Reference Guide.Sydney: The New South Wales Department of Health; 2009.

59 Sanches M, Marques AP, Ortegosa S, Freirias A, Uchida R, Tamai S. O exame do estado mental. É possível sistematizá-lo? Arq Med Hosp Fac Cienc Med Santa Casa São Paulo. 2005;50:18-23.

60 Xavier RM, Dora JM, Souza CFM, Barros E. Laboratório na prática clínica consulta rápida. $2^{a}$ ed. Porto Alegre: Artmed; 2011.

61 Baldacara L, Sanches M, Cordeiro DC, Jackoswski AP. Rapid tranquilization for agitated patients in emergency psychiatric rooms: a randomized trial of olanzapine, ziprasidone, haloperidol plus promethazine, haloperidol plus midazolam and haloperidol alone. Rev Bras Psiquiatr. 2011;33:30-9.

62 Zeller SL, Rhoades RW. Systematic reviews of assessment measures and pharmacologic treatments for agitation. Clin Ther. 2010; 32:403-25.

63 McAllister-Williams RH, Ferrier IN. Rapid tranquillisation: time for a reappraisal of options for parenteral therapy. $\mathrm{Br} \mathrm{J}$ Psychiatry. 2002;180:485-9.

64 Petit JR. Management of the acutely violent patient. Psychiatr Clin North Am.2005:28:701-11.

65 Ramadan M. Managing psychiatric emergencies. Internet J Emerg Med. 2006;4:1-9.

66 Stevenson S, Otto MP. Finding ways to reduce violence in psychiatric hospitals. J Healthc Qual. 1998;20:28-32.

67 Allen MH, Currier GW, Hughes DH, Reyes-Harde M, Docherty JP, Expert Consensus Panel for Behavioral E. The Expert Consensus Guideline Series. Treatment of behavioral emergencies. Postgrad Med. 2001; (Spec No):1-88; quiz 89-90.
68 Knox DK, Holloman GH Jr. Use and avoidance of seclusion and restraint: consensus statement of the American association for emergency psychiatry project Beta seclusion and restraint workgroup. West J Emerg Med. 2012;13:35-40.

69 Retsas AP. Survey findings describing the use of physical restraints in nursing homes in Victoria, Australia. Int J Nurs Stud. 1998;35:184-91.

70 Mott S, Poole J, Kenrick M. Physical and chemical restraints in acute care: their potential impact on the rehabilitation of older people. Int J Nurs Pract. 2005;11:95-101.

71 Fisher WA. Restraint and seclusion: a review of the literature. Am J Psychiatry. 1994;151:1584-91.

72 Odawara T, Narita H, Yamada Y, Fujita J, Yamada T, Hirayasu Y. Use of restraint in a general hospital psychiatric unit in Japan. Psychiatry Clin Neurosci. 2005;59:605-9.

73 Hübner-Liebermann B, SpiessI H, Iwai K, Cording C. Treatment of schizophrenia: implications derived from an intercultural hospital comparison between Germany and Japan. Int J Soc Psychiatry. 2005;51:83-96

74 Knutzen M, Sandvik L, Hauff E, Opjordsmoen S, Friis S. Association between patients' gender, age and immigrant background and use of restraint--a 2-year retrospective study at a department of emergency psychiatry. Nord J Psychiatry. 2007;61:201-6.

75 Martin V, Bernhardsgrütter R, Goebel R, Steinert T. The use of mechanical restraint and seclusion in patients with schizophrenia: a comparison of the practice in Germany and Switzerland. Clin Pract Epidemiol Ment Health. 2007;3:1.

76 Roberts D, Crompton D, Milligan E, Groves A. Reflection on the use of seclusion: in an acute mental health facility. J Psychosoc Nurs Ment Health Serv. 2009;47:25-31; quiz 50.

77 Irving K. Inappropriate restraint practices in Australian teaching hospitals. Aust J Adv Nurs. 2004;21:23-7.

78 Minnick AF, Mion LC, Johnson ME, Catrambone C, Leipzig R. Prevalence and variation of physical restraint use in acute care settings in the US. J Nurs Scholarsh. 2007;39:30-7.

79 Hendryx M, Trusevich Y, Coyle F, Short R, Roll J. The distribution and frequency of seclusion and/or restraint among psychiatric inpatients. J Behav Health Serv Res. 2010;37:272-81.

80 Araújo E, Martins E, Adams C, Coutinho E, Huf G. Inquérito sobre o uso de contenção física em um hospital psiquiátrico de grande porte no Rio de Janeiro. J Bras Psiquiatr. 2010;59:94-8.

81 Kaltiala-Heino R, Korkeila J, Tuohimaki C, Tuori T, Lehtinen V. Coercion and restrictions in psychiatric inpatient treatment. Eur Psychiatry. 2000;15:213-9.

82 Klimitz $\mathrm{H}$, Uhlemann $\mathrm{H}$, Fähndrich $\mathrm{E}$. [Are restraints used too frequently? Indications, incidence and conditions for restraint in a general psychiatric department. A prospective study]. Psychiatr Prax. 1998;25:235-9.

83 Alexander J, Tharyan P, Adams C, John T, Mol C, Philip J. Rapid tranquillisation of violent or agitated patients in a psychiatric emergency setting. Pragmatic randomised trial of intramuscular lorazepam v. haloperidol plus promethazine. Br J Psychiatry. 2004; 185:63-9.

84 Allen MH, Currier GW. Use of restraints and pharmacotherapy in academic psychiatric emergency services. Gen Hosp Psychiatry. 2004:26:42-9

85 Migon MN, Coutinho ES, Huf G, Adams CE, Cunha GM, Allen MH. Factors associated with the use of physical restraints for agitated patients in psychiatric emergency rooms. Gen Hosp Psychiatry. 2008;30:263-8

86 Simpson SA, Joesch JM, West, II, Pasic J. Risk for physical restraint or seclusion in the psychiatric emergency service (PES). Gen Hosp Psychiatry. 2014;36:113-8.

87 Beck NC, Durrett C, Stinson J, Coleman J, Stuve P, Menditto A. Trajectories of seclusion and restraint use at a state psychiatric hospital. Psychiatr Serv. 2008;59:1027-32.

88 Huf G, Coutinho ES, Adams CETREC-SAVE Collaborative Group. Physical restraints versus seclusion room for management of people with acute aggression or agitation due to psychotic illness (TREC-SAVE): a randomized trial. Psychol Med. 2012;42:2265-73.

89 Guedj MJ, Raynaud P, Braitman A, Vanderschooten D. [The practice of restraint in a psychiatric emergency unit]. Encephale. 2004; 30:32-9.

90 Guzman-Parra J, Aguilera Serrano C, García-Sánchez JA, PinoBenítez I, Alba-Vallejo M, Moreno-Küstner B, et al. Effectiveness of 
a Multimodal Intervention Program for Restraint Prevention in an Acute Spanish Psychiatric Ward. J Am Psychiatr Nurses Assoc. 2016;22:233-41.

91 Beghi M, Peroni F, Gabola P, Rossetti A, Cornaggia C. Prevalence and risk factors for the use of restraint in psychiatry: a systematic review. Riv Psichiatr. 2013;48:10-22.

92 Benjaminsen S, Gøtzsche-Larsen K, Norrie B, Harder L, Luxhøi A. Patient violence in a psychiatric hospital in Denmark: Rate of violence and relation to diagnosis. Nord J Psychiatry. 1996;50:233-42.

93 Guzman-Parra J, Guzik J, García-Sánchez JA, Pino-Benitez I, Aguilera-Serrano C, Mayoral-Cleries F. Characteristics of psychiatric hospitalizations with multiple mechanical restraint episodes versus hospitalization with a single mechanical restraint episode. Psychiatry Res. 2016;244:210-3.

94 Bowers L. Association between staff factors and levels of conflict and containment on acute psychiatric wards in England. Psychiatr Serv. 2009;60:231-9.

95 Alexander J. Patients' feelings about ward nursing regimes and involvement in rule construction. J Psychiatr Ment Health Nurs. 2006;13:543-53.

96 Smith $A D$, Humphreys M. Physical restraint of patients in a psychiatric hospital. Med Sci Law. 1997;37:145-9.

97 Bowers L, Van Der Merwe M, Nijman H, Hamilton B, Noorthorn E, Stewart D, et al. The practice of seclusion and time-out on English acute psychiatric wards: the City-128 Study. Arch Psychiatr Nurs. 2010;24:275-86.
98 Gudjonsson GH, Rabe-Hesketh S, Szmukler G. Management of psychiatric in-patient violence: patient ethnicity and use of medication, restraint and seclusion. Br J Psychiatry. 2004;184:258-62.

99 Husum TL, Bjorngaard JH, Finset A, Ruud T. A cross-sectional prospective study of seclusion, restraint and involuntary medication in acute psychiatric wards: patient, staff and ward characteristics. BMC Health Serv Res. 2010;10:89.

100 Steinert T, Bergbauer G, Schmid P, Gebhardt RP. Seclusion and restraint in patients with schizophrenia: clinical and biographical correlates. J Nerv Ment Dis. 2007;195:492-6.

101 Cowin L, Davies R, Estall G, Berlin T, Fitzgerald M, Hoot S. De-escalating aggression and violence in the mental health setting Int J Ment Health Nurs. 2003;12:64-73.

102 Jegede OO, Ahmed SF, Olupona T, Akerele E. Restraints utilization in a psychiatric emergency room. Int J Ment Health. 2017;46: 125-32.

103 Currier GW, Allen MH. Emergency psychiatry: physical and chemical restraint in the psychiatric emergency service. Psychiatr Serv. 2000;51:717-9.

104 Braga IP, de Souza JC, Leite MB, Fonseca VM, da Silva EM, Volpe FM. Contenção física no hospital psiquiátrico: estudo transversal das práticas e fatores de risco. J Bras Psiquiatr. 2016;65:53-9.

105 Baldaçara L, Diaz AP, Leite V, Pereira LA, dos Santos RM, Gomes Júnior VP, et al. Brazilian guidelines for the management of psychomotor agitation. Part 2. Pharmacological approach. Braz J Psychiatry. Forthcoming 2018. 